\title{
UTILIZAÇÃO DO TESTE DE RAIOS - X NA AVALIAÇÃO DOS EFEITOS DA DESSECAÇÃO E INFESTAÇÃO EM DIÁSPOROS DE CANELA-BATALHA - Cryptocarya aschersoniana Mez (LAURACEAE)
}

\author{
Rejane Elize Muxfeldt ${ }^{1}$, José Marcio Rocha Faria² ${ }^{2}$ Olívia Alvina Oliveira Tonetti ${ }^{3}$, Edvaldo Aparecido Amaral da Silva ${ }^{4}$
}

(recebido: 5 de agosto de 2010; aceito: 31 de agosto de 2012)

RESUMO: No presente trabalho, objetivou-se avaliar os efeitos da dessecação e identificar lesões por predação por insetos, em diásporos de canela-batalha (Cryptocarya aschersoniana Mez.), utilizando-se testes de raios X. Os danos provocados pela dessecação foram dimensionados nas imagens e associados à formação de plântulas. Diásporos recém-beneficiados (45\% de umidade e $37 \%$ de germinação) foram colocados para secar em sala climatizada $\left(20{ }^{\circ} \mathrm{C}\right.$ e $\left.60 \% \mathrm{UR}\right)$, dentro de bandejas plásticas em camada única. Posteriormente, com o intuito de acelerar o processo de secagem, foram colocados em caixas de secagem com solução saturada de hidróxido de sódio ( $28 \%$ UR) e amostrados com 45, 37, 35, 31 e $26 \%$ de umidade. Para as radiografias, utilizou-se a intensidade de radiação de $40 \mathrm{kVp}$ e tempo de exposição de 1,5 minutos. Posteriormente, as radiografias foram fotografadas e as imagens analisadas em computador, sendo medido o afastamento entre o endocarpo e a semente. As sementes foram classificadas em sementes intactas, sementes com afastamento parcial, sementes com afastamento total e sementes predadas. Os testes de germinação foram realizados sobre areia, em germinadores tipo Mangelsdorf a $25{ }^{\circ} \mathrm{C}$ e luz branca constante. Pelos resultados, observa-se que a germinação é comprometida quando o teor de água das sementes fica abaixo de $26 \%$. Nesse ponto, o afastamento entre o endocarpo e a semente é de $0,65 \mathrm{~mm}$. Houve uma correlação positiva entre a viabilidade das sementes, avaliada pelo teste de germinação, e o afastamento entre o endocarpo e a semente observado nas radiografias. A análise radiográfica possibilita identificar danos provocados por predação após infestação por insetos.

Palavras-chave: Análise radiográfica, sementes recalcitrantes, espécie florestal, predação de sementes.

\section{USE OF X-RAY ANALYSIS IN STUDIES OF THE EFFECTS OF DESICCATION ON DIASPORES OF CANELA-BATALHA (Cryptocarya aschersoniana Mez - LAURACEAE)}

\begin{abstract}
This study evaluated the effect of desiccation, and identified injuries and predation by insects in diaspores of "canelabatalha" (Cryptocarya aschersoniana Mez.) by using X-rays. The damages caused by desiccation were measured in the images and related to the formation of seedlings. Right after fruit depulping, the diaspores (endocarp plus seed) $45 \%$ moisture content-MC and 37 $\%$ germination) were dried in acclimatized room $\left(20^{\circ} \mathrm{C}\right.$ and $\left.60 \% \mathrm{RH}\right)$, inside of plastic trays in a single layer. Later, in order to speed up the drying process, they were placed in drying boxes with saturated solution of sodium hydroxide $(28 \%$ RH) and sampled with 45,37 , 35,31 and $26 \% \mathrm{MC}$. For the X-rays, an intensity of radiation of $40 \mathrm{KVp}$ was used and the time of exposition of 1.5 min. The radiographies were then photographed and the images analyzed in computer, being measured the separation between endocarp and the seed. The diaspores were classified as intact; with partial separation; with total separation and predated. The germination tests were carried out on sand, in incubators Mangelsdorf at $25{ }^{\circ} \mathrm{C}$ and constant white light. The results showed that the germination is affected when the diaspore MC reaches values below $26 \%$. In this point, the separation between endocarp and the seed is $0.65 \mathrm{~mm}$. There was a positive correlation between the viability of the seeds, evaluated through germination tests and the separation between endocarp and the seed, observed through X-rays. The radiographic analysis helps identify damage caused by predation after insect infestation.
\end{abstract}

Key words: Radiographic analysis, recalcitrant seeds, forest species, seed predation.

\section{INTRODUÇÃO}

Obter e manter elevada qualidade fisiológica de um lote de sementes é uma etapa crítica para assegurar e melhorar a produção de mudas. Sementes de espécies da família Lauraceae, em geral, não suportam longos períodos de armazenamento (CARVALHO et al., 2006), sendo que há relatos de que sementes de canela-batalha (Cryptocarya aschersoniana Mez.) são recalcitrantes (DAVIDE et al., 2003), mas podem ser armazenadas por até 180 dias, em

\footnotetext{
${ }^{1}$ Engenheira Florestal, Mestre em Engenharia Florestal - Fundação de Tecnologia do Acre/FUNTAC - Cx. P. 395 - $69917-100$ - Rio Branco, AC, Brasil - rejane.elize@ac.gov.br

${ }^{2}$ Engenheiro Florestal, Professor Doutor em Biologia de Sementes - Universidade Federal de Lavras/UFLA - Departamento de Ciências Florestais - Cx. P. 3037 - 3720-000 - Lavras, MG, Brasil - jmfaria@dcf.ufla.br

${ }^{3}$ Engenheira Florestal, Doutoranda em Engenharia Florestal - Universidade Federal de Lavras/UFLA - Departamento de Ciências Florestais - Cx. P. 3037 - 3720-000 - Lavras, MG, Brasil - oaotonetti@dcf.ufla.br

${ }^{4}$ Engenheiro Agrônomo, Professor Doutor em Fisiologia Vegetal - Universidade Estadual Paulista Júlio de Mesquita Filho - Faculdade de Ciências Agronômicas de Botucatu - Departamento de Produção Vegetal - 18603-970 - Botucatu, SP, Brasil - amaral@dcf.ufla.br
} 
sacos plásticos, em câmara fria $\left(5^{\circ} \mathrm{Ce} 70\right.$ \% UR), após leve secagem (até $35 \%$ de grau de umidade) (TONETTI, 2000). Ao contrário de sementes classificadas como ortodoxas, o grau crítico de umidade para as sementes recalcitrantes é alto, sendo que para a espécie já citada é em torno de $26 \%$ (DAVIDE et al., 1999).

Cryptocarya aschersoniana Mez. pertence à família Lauraceae, sendo conhecida como canela-batalha, canelafogo, canela-pimenta e canela-pururuca. Atinge entre 15-25 m de altura e sua ocorrência abrange os estados de Minas Gerais ao Rio Grande do Sul, na Floresta Ombrófila Densa da Floresta Atlântica aos sub-bosques de pinhais (LORENZI, 1998). O gênero Cryptocarya é pantropical, com aproximadamente 350 espécies, sendo cerca de 10 delas na América do Sul. Cryptocarya significa "fruto escondido" (do grego, kryptos escondido e káryon - fruto), em razão do completo envolvimento do fruto pelo eixo floral, principal caráter que distingue este gênero dos demais dentro da família (MORAES; ALVES, 2002). A espécie pertence ao grupo das clímax tolerantes à sombra (DAVIDE et al., 1995), seus frutos amadurecem nos meses de fevereiro a março, sendo consumidos por várias espécies animais (LORENZI, 1998).

Os frutos têm tamanho máximo de $3 \mathrm{~cm}$ de comprimento por 2 cm de diâmetro(MORAES; ALVES, 2002) contendo uma semente que se caracteriza como recalcitrante (CARVALHO; NAKAGAWA, 2000). Em alguns estudos com sementes de canela-batalha, são observados indícios de dormência, com aumentos significativos no percentual de germinação após armazenamento em curtoprazo e/ou secagem parcial (CARVALHOet al., 2006; DAVIDE et al., 1999).

Como é comum em espécies da família Lauraceae, as sementes de canela-batalha são bastante atacadas por insetos, não sendo esses danos facilmente visualizados pela observação externa (CARVALHO et al., 2009).

A análise de sementes utilizando-se o teste de raios $\mathrm{X}$ é uma técnica recomendada pela ISTA (International Rules For Seed Testing). Os raios X são ondas eletromagnéticas que trafegam à velocidade da luz, mas com variáveis comprimentos de onda (1/10.000 a 1/100.000 daquele da luz visível). Eles podem ser detectados em filmes fotossensíveis, formando a imagem do contraste das diferenças de densidade do objeto radiografado. As partes escuras da radiografia correspondem àquelas em que os raios $\mathrm{X}$ penetram mais facilmente, enquanto áreas mais claras representam partes mais densas da semente. Os raios $\mathrm{X}$ de baixa energia (grande comprimento) são apropriados para objetos pequenos, como sementes. A técnica baseiase na absorção da radiação em diferentes quantidades pelos diferentes tecidos das sementes, o que depende da espessura, da densidade e da composição desses tecidos, além do comprimento de onda da radiação (BINO et al., 1993; INTERNATIONAL RULES FOR SEED TESTING ISTA, 1999, 2004; SIMAK, 1991).

Autilização da radiografia para determinar a qualidade física das sementes tem como principais vantagens sobre os demais métodos a rapidez e a conservação da viabilidade das sementes testadas. Assim, é possível submetê-las a outros testes fisiológicos depois de radiografadas. Entre as espécies florestais, a técnica já foi utilizada com sucesso em sementes de Lithraea molleoides (MACHADO; CICERO, 2003), Peltophorum dubium (OLIVEIRA et al., 2003), Tabebuia serratifolia e T. impetiginosa (OLIVEIRA et al., 2004), Eremanthus incanus e E. erythropappus (TONETTI, 2004), Eugenia handroana (MASETTO, 2005) e espécies de lauráceas (CARVALHO et al., 2009).

Aliada à técnica de raios- $\mathrm{X}$, tem-se a possibilidade de efetuar a análise de imagens em computador, usando programas de análise de imagens, que permitem uma melhor visualização dos danos internos nas sementes. As mesmas podem ser examinadas individualmente em imagens capazes de indicar, com detalhes, a área danificada, a localização e a extensão do dano. As sementes podem ainda ser submetidas a testes fisiológicos e, dessa forma, permitir o estabelecimento de relações entre danos e prejuízos causados à qualidade das mesmas (CÍCERO; BANZATTO JÚNIOR, 2003).

A hipótese do presente trabalho foi a de que a quantificação dos danos ou modificações internas ocasionadas nas sementes pela dessecação, utilizando-se a análise de imagens de raios $\mathrm{X}$, pode servir como parâmetro para a avaliação da qualidade do lote de sementes de canela-batalha. Assim, os objetivos foram verificar, em graus de umidade pré-estabelecidos, as alterações morfológicas internas ocasionadas pela dessecação e a influência da infestação de larvas de insetos nas sementes, bem como a relação desses fatores na formação de plântulas.

\section{MATERIAL E MÉTODOS}

\subsection{Obtenção dos diásporos}

Frutos de Cryptocarya aschersoniana Mez. foram coletados de três árvores nas proximidades do campus da Universidade Federal de Lavras logo após a dispersão, em março de 2007. Efetuada a despolpa por maceração em peneira de malha de aço sob água corrente, os diásporos (unidades de dispersão contendo uma semente envolta

Cerne, Lavras, v. 18, n. 4, p. 657-666, out./dez. 2012 
por um endocarpo lenhoso) foram deixados sobre a mesma, em camada única, à sombra, até que perdessem a água superficial. Posteriormente, foram acondicionados em bandejas plásticas, em camada única, e levados para sala climatizada $\left(20^{\circ} \mathrm{Ce} 60 \% \mathrm{UR}\right)$.

\subsection{Determinação do grau de umidade}

O teor de água dos diásporos foi determinado em estufa ( $103 \pm 2{ }^{\circ} \mathrm{C}$ por 17 horas), conforme recomendações das Regras para Análise de Sementes (BRASIL, 1992). Foram utilizadas quatro repetições de cinco diásporos, cortados em várias partes com tesoura de poda. Os valores foram expressos em porcentagem, com base no peso úmido das sementes.

\subsection{Secagem dos diásporos}

Para determinar o efeito da secagem sobre a viabilidade das sementes, os diásporos foram secos, inicialmente em sala climatizada $\left(20^{\circ} \mathrm{Ce} 60 \%\right.$ UR). A partir da terceira semana, foram colocados em um "higrostat"(caixa de madeira com tampa e circulação de ar interna, provida por um pequeno ventilador que possibilita a homogeneização da umidade relativa dentro da caixa). Os diásporos foram espalhados em camada única, sobre uma tela removível, colocada a $20 \mathrm{~cm}$ acima do fundo da caixa, o qual continha uma bandeja plástica com solução saturada de hidróxido de sódio.

A umidade relativa no interior do "higrostat", proporcionada pelo hidróxido de sódio, foi mantida em torno de $28 \%$. Com base na curva de dessecação e germinação da espécie, descrita por Tonetti (2000), foram pré-determinados alguns graus de umidade para o estudo $(45 \%, 37 \%, 35 \%, 31 \%$ e 26\%). Para determinar os pontos de umidade pré-estabelecidos, realizaram-se pesagens sucessivas, com base no peso inicial utilizando-se a expressão abaixo (SECANDÉ et al., 2004):

Peso alvo $(\mathrm{g})=\frac{(100-\text { Umidade inicial }) \times \text { Peso inicial }}{(100-\text { Umidade desejada })}$

Os diásporos foram pesados semanalmente para o controle da umidade, determinada por meio da expressão descrita acima. Após atingirem o peso alvo, foram retiradas amostras para a determinação do grau de umidade, conforme as Regras para Análise de Sementes (BRASIL, 1992), teste de raios X e teste de germinação.

\subsection{Testes de raios $X$}

Para a obtenção das radiografias, utilizou-se o equipamento Faxitron HP, modelo 43855AX. O filme radiográfico utilizado foi o Kodak Min-R 2000, com dimensões de 18 x $24 \mathrm{~cm}$. Com base nos resultados de prétestes, foram definidos a intensidade de $40 \mathrm{kVp}$ e o tempo de 1,5 minutos como os melhores para a obtenção das imagens. Utilizaram-se amostras aleatórias de 256 diásporos, que foram dispostos em pequenas bandejas plásticas com oito canaletas cada, sendo quatro diásporos por canaleta, num total de oito bandejas por amostra (Figura 1-A). Os diásporos foram radiografados no momento em que atingiam os graus de umidade pré-definidos.
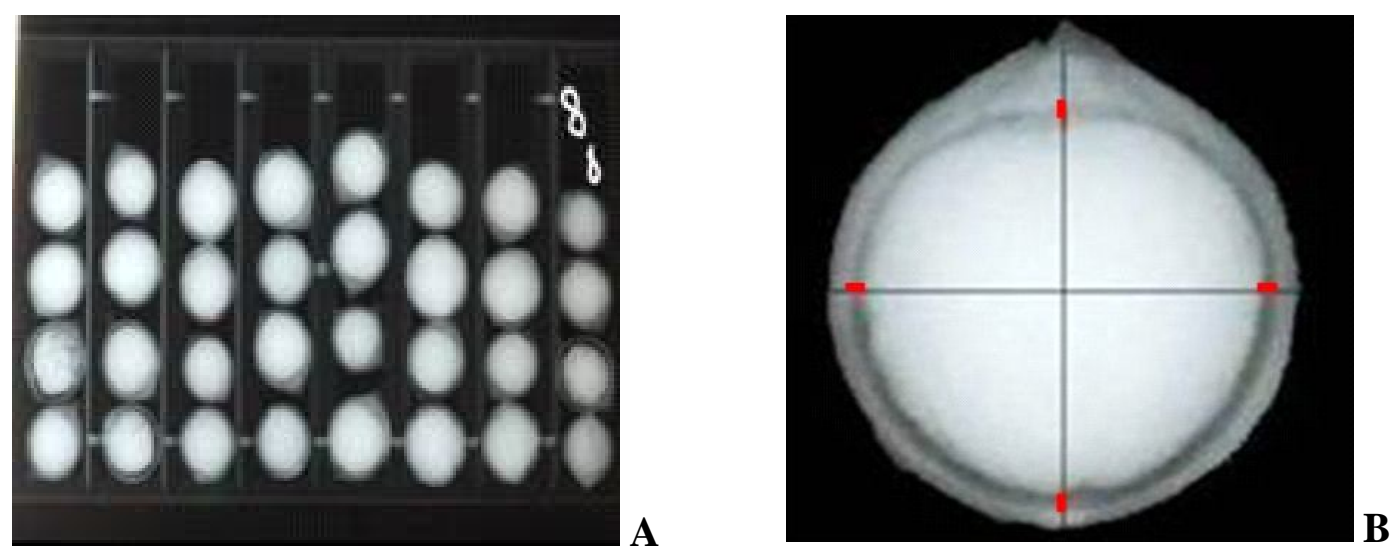

Figura 1 - A- radiografias dos diásporos; B- localização das medidas do afastamento entre endocarpo e semente (em vermelho), em sementes de Cryptocarya aschersoniana.

Figure 1 - A-radiographs of diaspores; B-location measures the distance between endocarp and seed (in red) in seeds of Cryptocarya aschersoniana. 


\subsection{Classificação das sementes de acordo com a análise das radiografias}

A cada ponto de umidade, as imagens foram analisadas e os diásporos classificados e separados nas categorias: sementes intactas (SI), com afastamento parcial (SAP), com afastamento total (SAT) e predadas (SP). Para cálculo do percentual de infestação, foram consideradas quatro repetições de 32 sementes em cada ponto de umidade.

\subsection{Testes de germinação}

Os diásporos classificados por categorias nas radiografias foram submetidos ao teste de germinação. Para tanto, foram lavados por dez minutos, em hipoclorito de sódio $1 \%$, enxaguados em água corrente e distribuídos entre areia lavada e autoclavada em bandejas plásticas ( 36,5 x 26,0 x 6,5cm), em quatro repetições de 25 sementes. Os testes foram conduzidos em germinadores Mangelsdorf, a $25^{\circ} \mathrm{C}$ e luz constante.

A avaliação da germinação foi realizada semanalmente e o critério de germinação considerado foi a formação de plântulas normais, segundo as Regras para Análise de Sementes (BRASIL, 1992). Ao final do teste, foram computadas plântulas normais, anormais e as sementes que não germinaram foram submetidas a um teste de corte (ISTA, 2005; JOSE et al., 2009) sendo consideradas dormentes as sementes que se apresentavam com os tecidos firmes e deterioradas aquelas com aspecto apodrecido. Os resultados foram expressos em porcentagem média de plântulas normais e a velocidade de germinação calculada pelo Índice de velocidade de germinação (IVG), proposto por Maguirre (1962).

\subsection{Análise das imagens}

As radiografias foram fotografadas com máquina digital, com resolução de 12 megapixels e as imagens transferidas para computador, com o uso do programa Adobe Photoshop ${ }^{\circledR} 7.0$, foram feitas quatro medidas dos afastamentos entre o endocarpo e a semente (Figura 1-B). Para cada ponto amostrado, foram medidos os afastamentos em 100 sementes. As medidas, obtidas em pixels pelo programa, foram convertidas em centímetros, com base na largura (conhecida) das bandejas utilizadas como suporte das sementes durante o teste de raios X.

\subsection{Curva de embebição}

Para a obtenção da curva de embebição, 40 diásporos foram numerados e dispostos em bandejas plásticas, sobre duas folhas de papel toalha (tipo germitest), saturadas com água destilada e cobertos com mais uma folha de papel toalha umedecido para manter a homogeneidade da umidade. As bandejas foram colocadas em germinador Mangelsdorf, a $25^{\circ} \mathrm{C}$. Nas primeiras 72 horas, foram feitas três pesagens diárias dos diásporos, individualmente, com balança analítica e, a partir daí, uma leitura diária, até o 22 dia, quando as leituras passaram a ser semanais, até que fosse observada a protrusão radicular.

\subsection{Análise dos dados}

Todos os experimentos tiveram delineamento inteiramente casualizado e os resultados obtidos foram submetidos à análise de variância pelo teste $\mathrm{F}$ ao nível de $5 \%$ de probabilidade com o uso do software Statistical Assistance Software - ASSISTAT (SILVA; AZEVEDO, 2006). As médias foram comparadas entre si pelo teste de Tukey, a $5 \%$ de probabilidade.

\section{RESULTADOS E DISCUSSÃO}

\subsection{Secagem dos diásporos}

O processo de secagem inicialmente foi bastante lento e, assim, optou-se por submeter os diásporos a um ambiente menos úmido em relação ao da sala climatizada. Porém, mesmo no higrostat, o tempo necessário para a obtenção dos pontos requeridos não diferiram consideravelmente dos obtidos na curva de dessecação observada por Tonetti (2000), em sala climatizada $\left(20^{\circ} \mathrm{Ce}\right.$ $60 \%$ UR). Estes apresentaram uma variação de \pm 2 pontos percentuais em relação à curva do trabalho anteriormente citado. Foram necessários 71 dias para que os diásporos atingissem $26 \%$ de umidade, o que pode estar relacionado à resistência do endocarpo. Apesar de lento, o processo de secagem se mostrou mais rápido se comparado ao trabalho de Hirano (2004), para a mesma espécie, em ambiente natural, a $22{ }^{\circ} \mathrm{C}$ e umidade relativa de $68 \%$, que obteve sementes com $31 \%$ de umidade, aos 60 dias e 28,5 $\%$ de umidade, aos 165 dias.

\subsection{Curva de embebição}

A curva de embebição (Figura 2) seguiu o padrão trifásico proposto por Bewley e Black (1994), sendo a fase I caracterizada pela rápida absorção de água, consequência do potencial matricial e que pode ocorrer independente da viabilidade e da dormência das sementes (exceto quando se tratar de dormência por impermeabilidade do tegumento à água). Embora Carvalho e Nakagawa (2000) relatem que a fase I seja relativamente rápida, com duração de uma ou

Cerne, Lavras, v. 18, n. 4, p. 657-666, out./dez. 2012 


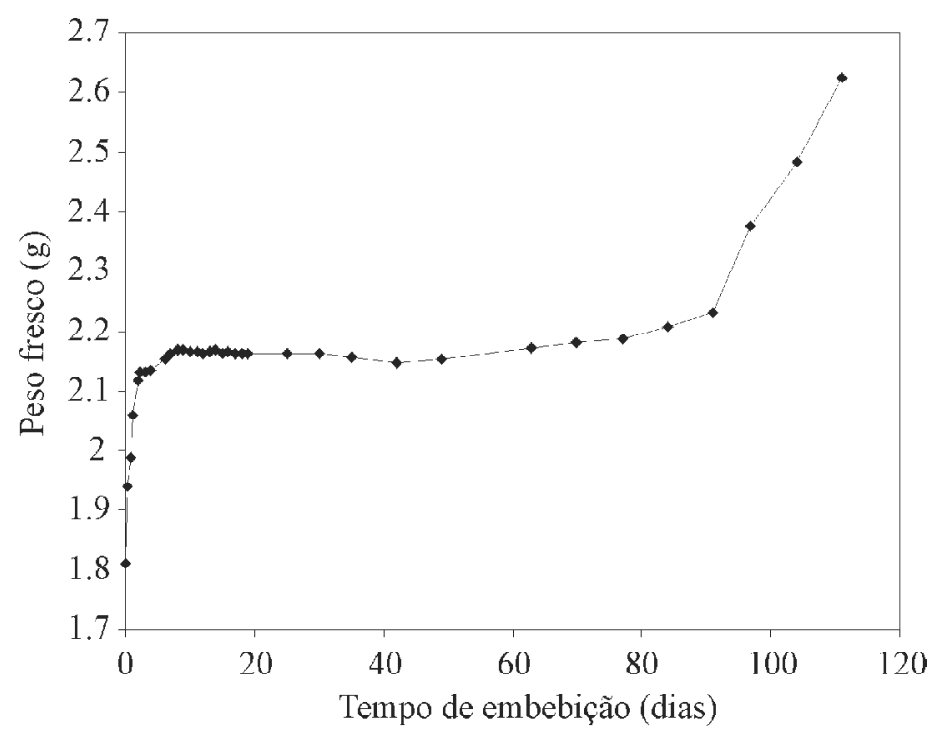

Figura 2 - Curva de embebição dos diásporos (teor de água inicial de $45 \%$ ) de Cryptocarya aschersoniana.

Figure 2 - Imbibition curve of diaspores (initial water content $45 \%$ ) of Cryptocarya aschersoniana.

duas horas, a fase de embebição no presente trabalho se estendeu por 72 horas. No entanto, os mesmos autores consideram que a velocidade de embebição está na dependência de outros fatores como a espécie, a natureza e a composição do tegumento.

Neste trabalho, a fase II teve duração de 89 dias, essa fase é estacionária e ocorre em função do balanço entre o potencial osmótico e o potencial de pressão, a semente absorve água lentamente e o eixo embrionário ainda não consegue crescer. Uma possível explicação para uma fase II tão extensa pode ser uma dormência embrionária, conforme sugerido por Carvalho et al. (2006) e Davide et al. (1999).

Aos 89 dias, teve início a fase III, na qual pode-se observar o novo aumento no peso fresco das sementes, com a emissão de raiz primária.

\subsection{Análise das radiografias}

Sementes recém-colhidas, com $45 \%$ de umidade, formaram uma imagem densa e contínua, sem separação visível destas com o endocarpo (Figura 3-A). Entre $37 \%$ e $26 \%$ de umidade, foi possível observar e dimensionar a linha de separação que é formada entre o endocarpo e a semente, causada pela dessecação (Figura 3-B a 3-F).

Com os resultados obtidos, verifica-se que o afastamento médio observado, entre $0,16 \mathrm{~mm}$ até próximo de $0,43 \mathrm{~mm}$ ( $31 \%$ de umidade), não implicou em queda da germinação. Ao contrário, a partir de 0,26 mm (35\% de umidade), observou-se um incremento no poder germinativo. Ao atingir $0,65 \mathrm{~mm}$ de afastamento, com as sementes com $26 \%$ de umidade, houve redução significativa no percentual de germinação (Figura 4).

O termo nível crítico de umidade define o limite acima do qual a semente pode ser dessecada, sem dano aparente (WALTERS, 2000). Resultados obtidos por Davide et al. (1999), para a espécie em questão, consideram um valor em torno de $26 \%$ como nível crítico de umidade e $20 \%$ como o grau letal de umidade (quando, então, ocorre a perda total da viabilidade). Os resultados aqui observados coincidem com os de Hirano (2004) em pesquisas realizadas sobre a dessecação e o armazenamento de canela-batalha, ao considerar que o nível crítico de umidade esteja entre $31,1 \%$ e $27,5 \%$ e que o nível letal esteja entre $25,8 \%$ e $22,8 \%$ de umidade.

Goodman et al. (2005), em estudos realizados sobre as aplicações da análise de imagens de raios X para avaliar a viabilidade em sementes de carvalho do norte (Quercus rubra L.), quantificaram os danos ocasionados pela redução do teor de água nos cotilédones dessa espécie. Os autores concluíram que a técnica é um melhor indicador da qualidade do lote, comparado com a determinação de umidade. Os mesmos autores, em trabalhos correlacionados, sugerem esse teste para espécies com sementes recalcitrantes grandes (GOODMAN et al., 2006).

Cerne, Lavras, v. 18, n. 4, p. 657-666, out./dez. 2012 


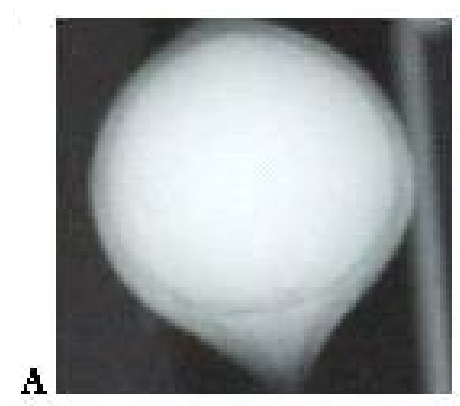

A

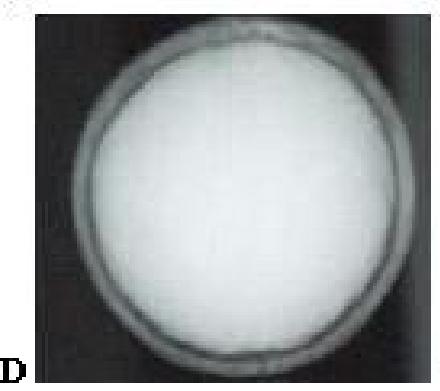

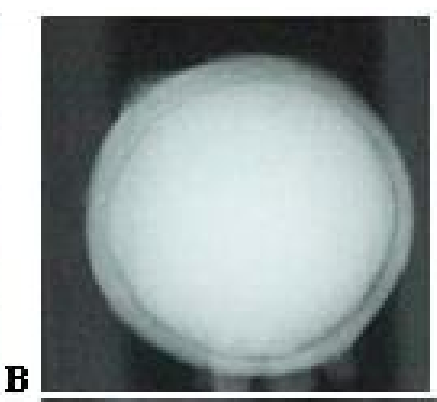

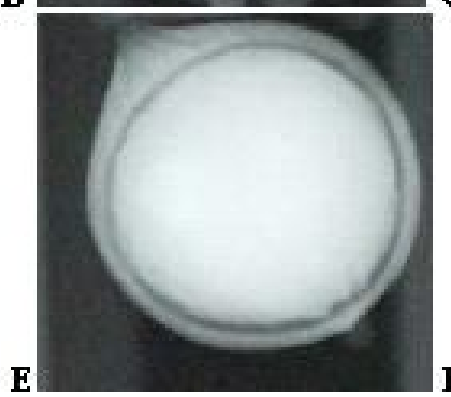

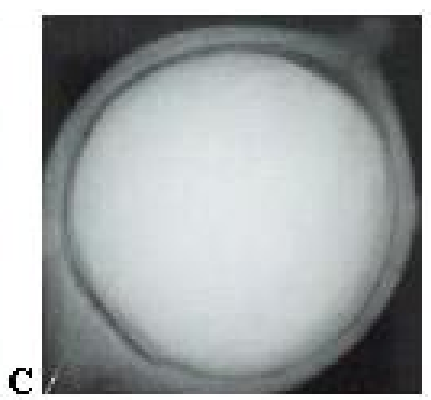

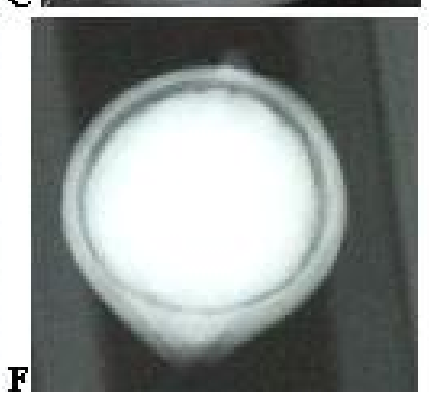

Figura 3 - Sementes de Cryptocarya aschersoniana classificadas pela análise radiográfica de acordo com a anatomia interna e umidade: A - semente intacta (45\%), B - semente com afastamento parcial (37\%), C - semente com afastamento parcial (35\%), D semente com afastamento total (35\%), E - semente com afastamento total (33\%) e F - semente com afastamento total (26\%).

Figure 3 - Seeds of Cryptocarya aschersoniana classified by radiographic analysis, according to the internal anatomy and humidity: A - intact seed (45\%), B - seed with partial removal (37\%), C - seed with partial removal (35\%) D - Seed with total clearance (35\%), E- seed with total clearance (33\%) and $F$ - seed with total clearance (26\%).

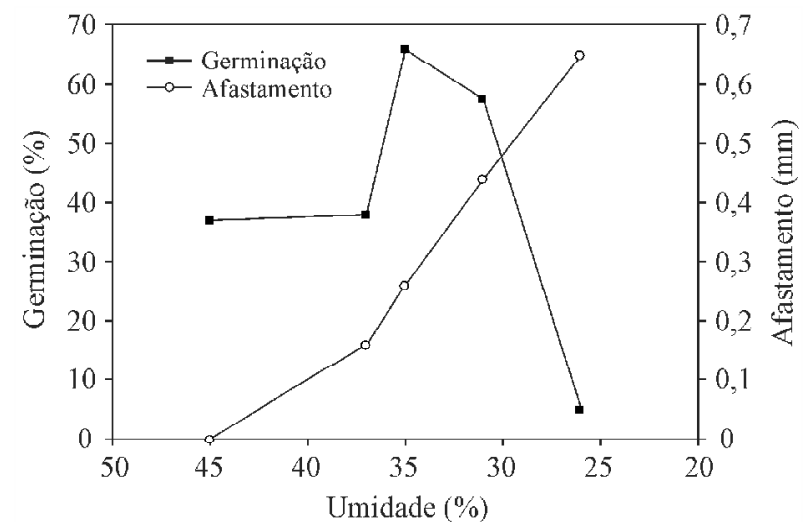

Figura 4 - Germinação (\%) e afastamento da semente em relação ao endocarpo (mm) dos diásporos de Cryptocarya aschersoniana nos diferentes graus de umidade estabelecidos. Regressões (Germinação: $y=-10,429 x 2+58,371 x-19,2 \mathrm{R} 2=0,7365$; Afastamento: $\mathrm{y}=0,3756 \operatorname{Ln}(\mathrm{x})-0,0577 \mathrm{R} 2=0,9)$.

Figure 4-Germination (\%) and removal of the seed in relation to the endocarp $(\mathrm{mm})$ of diaspores of Cryptocarya aschersoniana in different levels of humidity. Regressions (Germination: $y=-10.429+58.371 \times x 2-19.2 R 2=0.7365$; Clearance: $y=0.3756 \operatorname{Ln}(x)-0.0577 R 2=0.9)$.

Cerne, Lavras, v. 18, n. 4, p. 657-666, out./dez. 2012
Com os resultados obtidos, observa-se que médias de afastamento entre a semente e o endocarpo até próximo a $0,43 \mathrm{~mm}$ ( $31 \%$ de umidade), indicam melhoria nos índices de germinação. A partir de $0,65 \mathrm{~mm}$ (26\% de umidade), as sementes estão próximas do grau crítico de umidade para a espécie e, portanto com baixa qualidade do lote.

Neste trabalho, evidencia-se que a análise de radiografias, por meio de softwares que possibilitem uma melhor visualização e o dimensionamento de danos em sementes é bastante eficiente, considerando-se que é um método rápido e exato para avaliar o lote, em comparação com os demais métodos.

\subsection{Testes de germinação}

O experimento teve duração total de 165 dias. Os resultados encontrados neste trabalho coincidem com os obtidos por Davide et al. (1999) e Tonetti (2000), quando observaram, em Cryptocarya aschersoniana, um aumento na porcentagem de germinação após a secagem das sementes para um valor próximo de $35 \%$ de umidade. Os maiores percentuais de germinação no presente trabalho 
foram observados quando as sementes tiveram seu teor de água reduzido entre 35 e $31 \%$, ocorrendo o mesmo com o índice de velocidade de germinação (Figura 5). A mesma tendência foi observada com relação à formação de plântulas normais, indicando que uma redução do teor de água estimula o processo germinativo.

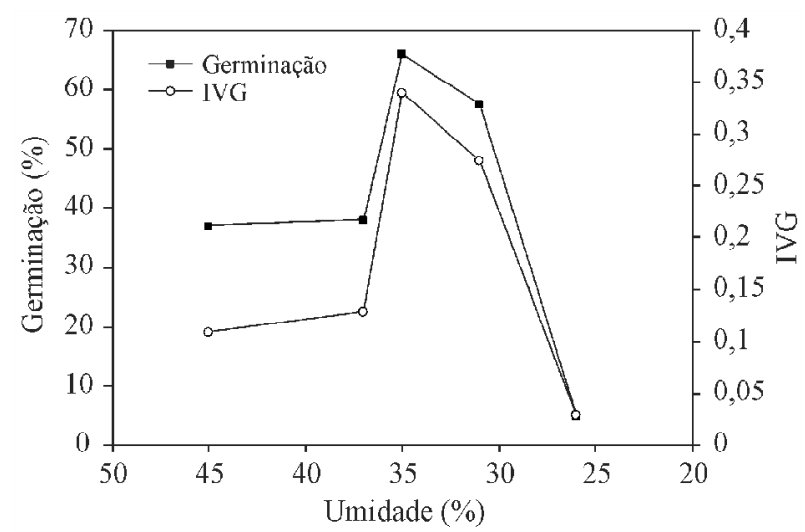

Figura 5 - Percentual de germinação e índice de velocidade de germinação dos diásporos de Cryptocarya aschersoniana nos diferentes graus de umidades estabelecidos. Regressões (Germinação: $\mathrm{y}=-10,429 \mathrm{x} 2+58,371 \mathrm{x}-19,2 \mathrm{R} 2=0,7365$; IVG: $\mathrm{y}=-0,0579 \mathrm{x} 2+0,3461 \mathrm{x}-0,224-\mathrm{R} 2=0,7159)$.

Figure 5 - Germination percentage and speed of germination of diaspores of Cryptocarya aschersoniana in different levels of humidity. Regressions (Germination: $y=-10.429 x 2+58.371 x-$ $19.2 R 2=0.7365 ; I V G: y=-0.0579 x 2+0.3461 x-0.224-R 2=$ $0.7159)$.
De acordo com Baskin e Baskin (1998), sementes de espécies da família Lauraceae apresentam dormência fisiológica. Outras espécies, como Aspidosperma cylindrocarpon, Tabebuia impetiginosa e Tabebuia serratifolia, também têm comportamento semelhante, como relatado por Carvalho et al. (2006), ao observar um aumento do poder germinativo para sementes submetidas à secagem $\left(20^{\circ} \mathrm{C}\right.$ e $60 \%$ UR) até o equilíbrio higroscópico.

Não houve diferença estatística nos índices de germinação e IVG entre as categorias sementes com afastamento parcial (SAP) e com afastamento total do endocarpo (SAT) nas amostras $31 \%$ de umidade (Tabela 1). Observa-se, portanto que a classificação quanto ao afastamento nesse grau de umidade não tem correspondência com a viabilidade das sementes. Ao final do teste de germinação (165 dias), nos graus de umidade de 45 e $37 \%$, foi observado, pelo teste de corte, alto percentual de diásporos com sementes dormentes (acima de $50 \%$ ), indicando a ocorrência de dormência fisiológica, o que foi reduzido nas sementes entre 35 e $31 \%$ de umidade (Tabela 1).

\subsection{Infestação}

Segundo Carvalho et al. (2009), a importância da detecção de sementes infestadas está na possibilidade do descarte das mesmas, melhorando a qualidade do lote, o que contribui para a conservação das sementes durante o armazenamento. Além disso, a eliminação das sementes infestadas evita a transferência de insetos para outras regiões.

Tabela 1 - Percentual de diásporos dormentes e deteriorados ao final do teste de germinação, nas categorias: sementes intactas (SI), sementes com afastamento parcial (SAP), sementes com afastamento total (SAT) e plântulas normais de Cryptocarya aschersoniana, nos diferentes graus de umidades amostrados.

Table 1 - Percentage of diaspores dormant and damaged at the end of the germination test in the various categories: intact seeds (SI), seeds with partial removal (SAP), seeds with total clearance (SAT) and normal seedlings of Cryptocarya aschersoniana in different degrees of moisture sampled.

\begin{tabular}{ccccc}
\hline \multirow{2}{*}{$\begin{array}{c}\text { Umidade } \\
(\%)\end{array}$} & Classes & \multicolumn{2}{c}{ Diásporos } & \multirow{2}{*}{ Plântulas normais } \\
\cline { 3 - 4 } 45 & SI & Dormentes & Deteriorados & $29 \mathrm{ab}$ \\
37 & SAP & $58 \mathrm{~b}$ & $5 \mathrm{ab}$ & $30 \mathrm{ab}$ \\
35 & SAP & $5 \mathrm{~d}$ & $5 \mathrm{ab}$ & $61 \mathrm{a}$ \\
31 & SAP & $22 \mathrm{~cd}$ & $29 \mathrm{a}$ & $52 \mathrm{a}$ \\
31 & SAT & $19 \mathrm{~cd}$ & $22 \mathrm{ab}$ & $51 \mathrm{a}$ \\
26 & SAT & $95 \mathrm{a}$ & 0 & $5 \mathrm{~b}$ \\
\hline
\end{tabular}

Médias seguidas pela mesma letra na coluna não diferem estatisticamente entre si, pelo teste de Tukey, a 5\% de probabilidade. Means followed by the same letter in column are not statiscically different among themselves by Tukey test at 5\% probability. 
As sementes de canela-batalha são atacadas por insetos pertencentes à ordem Coleoptera, família Curculionidae, que se desenvolvem nointerior dos diásporos. Para a espécie estudada, o teste de raios $\mathrm{X}$ na intensidade de radiação utilizada, em todos os níveis de amostragem efetuados, favoreceu a visualização das sementes predadas, mostrando-se eficaz na avaliação de sementes infestadas. Isso possibilita a eliminação das mesmas, promovendo a melhoria do lote por meio do descarte das sementes com danos ocasionados pela infestação, logo após a colheita.

Apesar do elevado teor de água (45,21\%), foi possível visualizar as galerias formadas pelas larvas do inseto (Figura 6). Nas amostras observadas com esse grau de umidade, $17,2 \%$ das sementes apresentavam sinais de predação, conforme foi possível identificar pelas análises de raios X. As sementes classificadas como predadas nas amostras com 45 e $37 \%$ umidade foram colocadas para germinar, obtendose $5 \%$ de germinação para as recém-colhidas e $0 \%$ para as sementes com $37 \%$ de umidade. Verifica-se, assim, que a presença das larvas afeta significativamente a germinação, diminuindo a qualidade do lote.
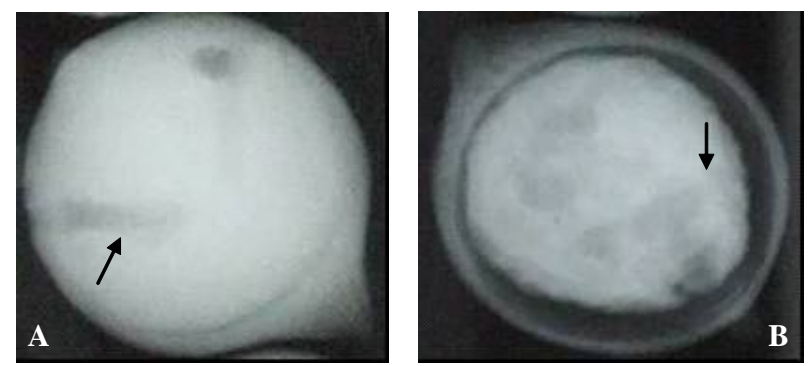

Figura 6 - Sementes de Cryptocarya aschersoniana predadas por insetos. Visualização das galerias efetuadas pela larva do inseto: A- $45 \%$ de umidade e B - 33\% de umidade.

Figure 6 - Seeds of Cryptocarya aschersoniana predated by insects. Visualization of the galleries made by insect larvae: A$45 \%$ humidity and B - 33\% humidity.

O ataque de insetos dessa família também foi observado em sementes de outras espécies da família Lauraceae, como, Nectandra nitidula, Nectandra lanceolata e Nectandra grandiflora (CARVALHO et al., 2009), em Aniba roseodora (ROSA; OHASHI, 1999), além da própria Cryptocarya aschersoniana (ALMEIDA, 2001).

\section{CONCLUSÕES}

Em sementes de Cryptocarya aschersoniana, o uso do teste de raios $\mathrm{X}$ ajustado em $40 \mathrm{kVp}$ e 1,5 minutos de exposição mostrou-se eficaz para a avaliação dos danos ocasionados por secagem e infestação por insetos.

Em sementes Cryptocarya aschersoniana, o afastamento entre a semente e o endocarpo até o valor de $0,43 \mathrm{~mm}$ ( $31 \%$ de umidade) é indício de melhoria dos índices de germinação. Acima desse valor de afastamento, a qualidade é afetada negativamente e, ao atingir $0,65 \mathrm{~mm}$ (26\% de umidade), a germinação não ocorre.

\section{REFERÊNCIAS}

ALMEIDA, L. P. de. Germinação, crescimento inicial e anatomia foliar de plantas jovens de Cryptocarya aschersoniana Mez. sob diferentes níveis de radiação. 2001. 96 p. Dissertação (Mestrado em Fisiologia Vegetal) Universidade Federal de Lavras, Lavras, 2001.

BASKIN, C. C.; BASKIN, J. M. Seeds ecology, biogeography, and evolution of dormancy and germination. San Diego: Academic, 1998. 666 p.

BEWLEY, J. D.; BLACK, M. Seeds: physiology of development and germination. $2^{\text {nd }}$ ed. New York: Plenum, 1994. $445 \mathrm{p}$.

BINO, R. J.; AARTSE, J. W.; BURG, W. J. van der. Nondestructive X-ray of Arabidopsis embryo mutants. Seed Science Research, Wallingford, v. 3, n. 2, p. 67-170, June 1993.

BRASIL. Ministério da Agricultura e da Reforma Agrária. Regras para análise de sementes. Brasília, 1992. 365 p.

CARVALHO, L. R.; CARVALHO, M. L. M.; DAVIDE, A. C. Utilização do teste de raios-X na avaliação da qualidade de sementes de espécies florestais de Lauraceae. Revista Brasileira de Sementes, Brasília, v. 31, n. 4, p. 57-66, 2009.

CARVALHO, L. R.; SILVA, E. A. A.; DAVIDE, A. C.

Classificação de sementes florestais quanto ao comportamento no armazenamento. Revista Brasileira de Sementes, Brasília, v. 28, n. 2, p. 15-25, 2006.

CARVALHO, N. M.; NAKAGAWA, J. Sementes: ciência, tecnologia e produção. 4. ed. Jaboticabal: FUNEP, 2000. 588 p.

CÍCERO, S. M.; BANZATTO JÚNIOR, H. L. Avaliação do relacionamento entre danos mecânicos e vigor, em sementes de milho, por meio da análise de imagens. Revista Brasileira de Sementes, Pelotas, v. 25, n. 1, p. 25-28, jun. 2003. 
DAVIDE, A. C.; CARVALHO, L. R. C.; CARVALHO, M. L. M.; GUIMARÃES, R. M. Classificação fisiológica de sementes de espécies florestais pertencentes à família Lauraceae quanto à capacidade de armazenamento. Cerne, Lavras, v. 9, n. 1, p. 29-35, 2003.

DAVIDE, A. C.; FARIA, J. M. R.; BOTELHO, S. A. Propagação de espécies florestais. Belo Horizonte: CEMIG/UFLA/FAEPE, 1995. $41 \mathrm{p}$.

DAVIDE, A. C.; TONETTI, O. A. O.; CARVALHO, L. R. Efeitos da dessecação na viabilidade de sementes de canelabatalha (Cryptocarya aschersoniana $\mathrm{Mez}$ - Lauraceae). Informativo ABRATES, Brasília, v. 9, n. 1/2, p. 175, jul./ago. 1999.

GOODMAN, R. C.; JACOBS, D. F.; KARRFALT, R. P. Evaluating desiccation sensitivity of Quercus rubra acorns using X-ray image analysis. Canadian Journal of Forest Research, Ottawa, v. 5, n. 12, p. 2823-2831, Dec. 2005.

GOODMAN, R. C.; JACOBS, D. F.; KARRFALT, R. P. Using X-ray image analysis to assess the viability of northern red oak acorns: implications for seed handlers. In: USDA FOREST SERVICE, 2006, Washington. Proceedings... Washington, 2006.

HIRANO, E. Maturação fisiológica, tolerância à dessecação e conservação de sementes de lauráceas da mata de araucária de Santa Catarina. 2004. 143 p. Tese (Doutorado em Agronomia) - Universidade Federal do Paraná, Curitiba, 2004.

INTERNATIONAL RULES FOR SEED TESTING. Seed science and technology. Zürich, 1999. 333 p. Supplement.

\section{INTERNATIONAL RULES FOR SEED TESTING. Seed} science and technology. Zürich, 2004. 180 p.

\section{INTERNATIONAL RULES FOR SEED TESTING. Seed science and technology. Zürich, 2005. Suplement.}

JOSE, A. C.; LIGTERINK, W.; DAVIDE, A. C.; SILVA, E. A. A. da; HILHORST, H. W. M. Changes in gene expression during drying and imbibition of desiccation sensitive Magnolia ovate (A. St. - Hil.) Spreng. Seeds. Revista Brasileira de Sementes, Londrina, v. 31, n. 1, p. 270-280, 2009.
LORENZI, H. Árvores brasileiras: manual de identificação e cultivo de plantas arbóreas nativas do Brasil. Nova Odessa: Plantarum, 1998. 352 p.

MACHADO, C. F.; CÍCERO, S. M. Aroeira-branca (Litthraea molleoides (Vell.) Engl. - Anacardiaceae) seed quality evaluation by the X-ray test. Scientia Agricola, Piracicaba, v. 60, n. 2, p. 393-397, abr./jun. 2003.

MAGUIRRE, J. D. Speed of germination-aid seedling emergence and vigor. Crop Science, Madison, v. 2, n. 2, p. 176-177, Mar./Apr. 1962.

MASETTO, T. E. Estudos da sensibilidade à dessecação em sementes de Eugenia handroana D. Legrand (Myrtaceae). 2005. 60 p. Dissertação (Mestrado em Engenharia Florestal) - Universidade Federal de Lavras, Lavras, 2005.

MORAES, P. L. R.; ALVES, M. C. Biometria de frutos e diásporos de Cryptocarya aschersoniana Mez e Cryptocarya moschata Nees (Lauraceae ). Biota Neotropica, São Paulo, v. 2, n. 1, p. 39-49, 2002.

OLIVEIRA, L. M. de; CARVALHO, M. L. M.; DAVIDE, A. C. Utilização do teste de raios-X na avaliação da qualidade de sementes de canafístula (Peltophorum dubium (Sprengel) Taubert). Revista Brasileira de Sementes, Pelotas, v. 25, n. 1, p. 116-120, jul. 2003.

OLIVEIRA, L. M. de; CARVALHO, M. L. M.; GUIMARÃES, R. M.; MASETTO, T. E. Avaliação da qualidade de sementes de Tabebuia serratifolia Vahl Nich. e T. impetiginosa (Martius ex A. P. de Candolle) Standley - (Bignoniaceae) pelo teste de raios X. Revista Brasileira de Sementes, Pelotas, v. 26, n. 2, p. 138-143, dez. 2004.

ROSA, L. dos S.; OHASHI, S. T. Influência do substrato e do grau de maturação dos frutos sobre a germinação do pau-rosa (Aniba rosaeodora Ducke). Revista de Ciências Agrárias, Belém, n. 31, p. 49-55, jan./jun. 1999.

SACANDÉ, M.; JOKER, D.; DULLOO, M.; THOMSEN, K. A. (Ed.). Comparative storage biology of tropical tree seeds. Roma: International Plant Genetic Resources Institute, 2004. 363 p.

Cerne, Lavras, v. 18, n. 4, p. 657-666, out./dez. 2012 
SILVA, F. de A. S. e; AZEVEDO, C. A. V. de. A new version of ASSISTAT: Statistical Assistance Software. In: WORLD CONGRESS ON COMPUTERS IN AGRICULTURE, 4., 2006, Orlando. Proceedings... Orlando: American Society of Agricultural Engineers, 2006. p. 393-396.

SIMAK, M. Testing of forest tree and shrub seeds by Xradiography. In: GORDON, A. G.; GOSLING, P.; WANG, B. S. P. (Ed.). Tree and shrub seed handbook. Zurich: ISTA, 1991. p. $14-28$

TONETTI, O. A. O. Melhoria da qualidade física e estudo da germinação de sementes de candeia (Eremanthus incanus (Less.) e Eremanthus erythropappus (DC.) Mac. Leish). 2004. 81 p. Dissertação (Mestrado em Ciências Florestais) - Universidade Federal de Lavras, Lavras, 2004.

TONETTI, O. A. O. Tolerância à dessecação e armazenamento de sementes de canela-batalha (Cryptocarya aschersoniana - MEZ). 2000. 22 p. Monografia (Graduação em Engenharia Florestal) - Universidade Federal de Lavras, Lavras, 2000.

WALTERS, C. Levels of recalcitrance in seeds. Revista Brasileira de Fisiologia Vegetal, Lavras, v. 2, p. 7-21, dez. 2000. Edição especial. 